\title{
Teaching Reform and Exploration of Comprehensive Design Course for Chemical Equipment*
}

\author{
$\mathrm{Na} \mathrm{Xiao}$ \\ School of Mechanical Engineering \\ Huanghe Science and Technology University \\ Zhengzhou, 450000 China
}

\author{
Hui Li \\ School of Mechanical Engineering \\ Huanghe Science and Technology University \\ Zhengzhou, China 450000
}

\author{
Chunxia $\mathrm{He}$ \\ School of Mechanical Engineering \\ Huanghe Science and Technology University \\ Zhengzhou, China 450000
}

\begin{abstract}
Comprehensive Design of Chemical Equipment is a core professional course for process equipment and control engineering majors, which plays a leading role in the entire teaching system. This paper discusses how to adopt projectbased teaching in the course teaching of comprehensive design of chemical equipment, improve the effect of course teaching, mobilize students 'interest in learning, enhance the practicability of course, improve students' design ability and create thinking to carry on the course teaching reform and exploration.
\end{abstract}

Keywords—chemical equipment; teaching reform; exploration; effective approaches

\section{INTRODUCTION}

The comprehensive design of chemical equipment is a professional and practical course for process equipment and control, providing the necessary theoretical knowledge and professional skills for training over-control professionals. Through this course, students are required to have the ability of structural design, material selection, process analysis and process management of chemical equipment, and to master the corresponding working principles of chemical equipment. Through this course, students are required to have the ability of chemical equipment design, material selection, process analysis and process management, and the knowledge of the working principles of chemical equipment.

\section{ANALYSIS OF CURRENT SitUATION OF SimILAR COURSES AT HOME AND ABROAD}

According to the present situation, existing problems and future development of chemical and mechanical higher education at home and abroad, China established the undergraduate program of "Process Equipment and Control Engineering" in March 1998. Taking this as an opportunity,

*Fund project: This paper is one of the research achievements of the 2017 teaching reform project of Huanghe S \& T University, "Comprehensive Design of Chemical Equipment" (Project No. JCXK201715); The one of the achievements of the ninth batch of Henan province machinery manufacturing and automation key discipline construction project. the Teaching Steering Committee has formulated the general idea of "the higher education for the 21 st century "process equipment and control engineering' undergraduate major construction and talent training". The idea requires all colleges and universities to start from the transformation of traditional educational ideas, broaden the scope of professionalism, aim at cultivating quality, knowledge and ability of students, and develop advanced manufacturing technology as the starting point for the reform and development of this profession. Reorganize the curriculum system and strengthen the general basic theory. While strengthening the teaching of general basic theory and practice, reducing the weight of professional courses to strengthen the space for self-study, free discussion and development of students, so as to gradually establish the spirit of undergraduate students' courage to think and innovate. At present, relevant courses are offered in related majors, such as Zhejiang University in China [1].

\section{THE GENERAL IDEA OF CURRICULUM REFORM}

The general idea of the course teaching of chemical equipment comprehensive design course is that the basic starting point is chemical process knowledge, chemical principle knowledge and fluid mechanics knowledge. Based on mathematical modeling, structural design and case analysis, the theory teaching and practice teaching are carried out synchronously. With the link of innovative design and professional qualification certificate, the training of engineering practice ability is strengthened and the training of engineering consciousness are carried out in the teaching links of each module to effectively improve the innovative consciousness and entrepreneurial ability of students.

\section{THE CONTENT OF CURRICULUM REFORM}

Guided by the practical teaching of case analysis, based on the learning and cognitive rules of students, establish a phased, multilevel, modular, open, comprehensive project practice teaching system [2]. 
In order to facilitate teaching and enable students to master the design of the most basic and typical equipment, this course selects common typical chemical equipment such as heat exchanger, reaction kettle, storage tank, distillation tower and so on as the carrier of practical design project teaching, in order to achieve the goal of practical design project teaching. The teaching process includes the following five aspects:

- The analysis of the practical design project. According to each teaching practice design project, analyze the actual process environment applied by the project, the purpose of the project teaching, the knowledge involved in the project and the ability to master.

- The explanation of classroom theory. Combine the project and explain the theoretical knowledge involved in the project through model, video or multimedia courseware. The explanation of theoretical knowledge requires the theory to be combined with reality and the practicality of the principle.

- Classroom simulation explanation. Each project should have a student's simulation explanation, so that students experience and master the learning content, and make the teaching, learning, and practice are integrated.

- Design each project independently after class. Project analysis, equipment structure design, material selection and mathematical modeling are carried out for each project.

- Integrated project design. After each teaching practice design project module is completed, a comprehensive project involving the knowledge and skills of all modules is designed to allow students to complete the project requirements independently.

\section{TEACHING REFoRm MethodS AND AsSESSMENT METHODS}

\section{A. Reform Method}

- The teaching process is oriented to the simulation design project, and the self-learning around the completion of the project is the core learning method;

- Provide macro guidance to the students' practical process through a series of special lectures;

- Micro-instruction of the students' practice process through grouping and individual coaching;

- Hold a staged design results report meeting to cultivate communication skills and supervise the teaching process in an orderly manner;

- Introduction of computer-assisted teaching techniques.

\section{B. Assessment Method}

This course is a discipline engineering skill training course. Students learn the design methods and tools of modern (Chemical Engineering) through the practical learning process of the design project, understand the process of chemical design work, the content of work, the method of designing the document, and learn the whole process of chemical engineering design from the overall practice. CAD tool software and a basic chemical CAD method are used to cultivate the ability of using the basic theory of chemical engineering to solve the specific engineering problems.

Comprehensive assessment is carried out with multiple assessment methods, and different assessment methods are adopted for different courses and different forms of design courses, and innovation is encouraged.

- Taking the method of combining the usual performance with the final examination results, the usual performance for $30 \%$ of the total course results. The usual performance is mainly about student attendance, classroom discussions and homework.

- The results of the design part are reflected in the form of paper and drawing.

\section{EXPECTED TEACHING EFFECT AND FEATURE DEMONSTRATION}

\section{A. Driven by Case Analysis, Forming a Training Mode with Distinctive Innovative Talents}

Absorb the new achievements of scientific research and teaching, update the practice content, and increase the comprehensive design through project-based practical teaching methods. Form an atmosphere with a wide range of teaching coverage, extensive and refined design projects, strong interest in learning and active learning. Cultivate process equipment and control engineering professionals with high design capabilities, analytical problem-solving skills, and practical innovation capabilities.

\section{B. The Quality of Entrepreneurial Talent Training Has Improved Significantly}

Through the project-driven practical curriculum reform, students will be the main body, realize the close integration of schools and enterprises, and jointly cultivate qualified personnel who have achieved the standards and requirements for the training of talents by schools and enterprises. Carry out the teaching operation mode of "teaching, learning, and doing", and realize the training goal of "doing in learning, comprehending in learning, and learning in comprehension", to enhance the adaptability of the graduates, the ability of creative thinking and the competitiveness of the employment, the seamless docking of the graduates and the enterprises will be achieved, and the quality of the training of the professional and entrepreneurial talents is obviously improved. [3].

\section{Inspiring Students' Potential for Innovation and Entrepreneurship}

Introduced a modern design method based on computer process simulation technology in the teaching content, and started with learning advanced process simulation software tools. Combined with the design of the project to carry out the training of practical application ability, students can truly have 
the basis of modern design, and adapt well to the needs of talents in the current chemical industry in China.

The teaching guiding ideology of training engineering application ability and comprehensive quality is highlighted, and the teaching mode under the guidance of practical teaching under the guidance of classroom instruction and the independent study under the guidance of teachers is used as the main teaching mode. The students' learning intensity has greater elastic space, which is beneficial to the development of individual potential; the teaching methods such as less talk and more practice, collaborative learning, and other measures to stimulate students 'learning enthusiasm and initiative; comprehensive use of modern education technology such as multimedia teaching, network teaching, and computer teaching.

\section{CONCLUSION}

Through the project-based teaching method, the students' interest and enthusiasm are continuously improved, and various chemical equipments are presented in front of the students more intuitively. Combining different process environments and design parameters, students can understand the comprehensive design process of chemical equipment. Through this course reform, students can better grasp the basic theory, methods and corresponding specifications of chemical equipment design, fully understand the structural characteristics and operation rules of process equipment, and learn the general engineering design methods for the classic process equipment such as heat transfer equipment, mass transfer equipment, storage equipment and reaction equipment and design procedure steps.

\section{REFERENCES}

[1] Chen Lian. Some Attempts and Practices in the Reform of Chemical Equipment Machinery Basic Teaching [J]. Higher Education in Chemical Engineering, 2012, (1)19-21.

[2] Zhao Bin, Zhang Herui. Reflections on the Teaching Reform of the Course of Mechanical Equipment Mechanical Design Foundation[J]. Adult Education of Hebei University of Technology, 2010, 20(2).

[3] Li Hong, Sun Hongyan, Liu Liguo et al. Research and Practice on the Design Reform of Mechanical Equipment Mechanical Basic Courses[J]. Heilongjiang Education, 2013, (10): 41-42. 